\title{
Increased protein synthesis by cells exposed to a 1,800-MHz radio-frequency mobile phone electromagnetic field, detected by proteome profiling
}

\author{
Christopher Gerner • Verena Haudek • Ulla Schandl • \\ Editha Bayer • Nina Gundacker · Hans Peter Hutter • \\ Wilhelm Mosgoeller
}

Received: 8 July 2009 / Accepted: 14 January 2010 / Published online: 10 February 2010

(c) The Author(s) 2010. This article is published with open access at Springerlink.com

\begin{abstract}
Purpose To investigate whether or not low intensity radio frequency electromagnetic field exposure (RF-EME) associated with mobile phone use can affect human cells, we used a sensitive proteome analysis method to study changes in protein synthesis in cultured human cells.

Methods Four different cell kinds were exposed to $2 \mathrm{~W} / \mathrm{kg}$ specific absorption rate in medium containing ${ }^{35} \mathrm{~S}$-methionine/cysteine, and autoradiography of 2D gel spots was used to measure the increased synthesis of individual proteins.

Results While short-term RF-EME did not significantly alter the proteome, an 8-h exposure caused a significant increase in protein synthesis in Jurkat T-cells and human fibroblasts, and to a lesser extent in activated primary human mononuclear cells. Quiescent (metabolically inactive) mononuclear cells, did not detectably respond to RFEME. Since RF exposure induced a temperature increase of less than $0.15^{\circ} \mathrm{C}$, we suggest that the observed cellular response is a so called "athermal" effect of RF-EME.
\end{abstract}

Electronic supplementary material The online version of this article (doi:10.1007/s00420-010-0513-7) contains supplementary material, which is available to authorized users.

C. Gerner · V. Haudek · U. Schandl · E. Bayer $\cdot$ N. Gundacker .

W. Mosgoeller $(\square)$

Department Med.-1, Institute of Cancer Research,

Medical University Vienna, Borschkegasse 8a,

1090 Vienna, Austria

e-mail: wilhelm.mosgoeller@meduniwien.ac.at

H. P. Hutter

Center for Public Health, Institute of Environmental Health,

Medical University Vienna, Kinderspitalgasse 15,

1095 Vienna, Austria
Conclusion Our finding of an association between metabolic activity and the observed cellular reaction to low intensity RF-EME may reconcile conflicting results of previous studies. We further postulate that the observed increased protein synthesis reflects an increased rate of protein turnover stemming from protein folding problems caused by the interference of radio-frequency electromagnetic fields with hydrogen bonds. Our observations do not directly imply a health risk. However, vis-a-vis a synopsis of reports on cells stress and DNA breaks, after short and longer exposure, on active and inactive cells, our findings may contribute to the re-evaluation of previous reports.

Keywords GSM mobile phone $\cdot$ Protein synthesis $\cdot$ Stress proteins $\cdot$ Toxicology

\section{Abbreviations \\ RF-EME Radiofrequency electromagnetic exposure SAR Specific absorption rate}

\section{Introduction}

Whether or not low intensity radiofrequency electromagnetic field exposure (RF-EME) associated with the use of GSM-1800 mobile phones can have direct effects on cells is a matter of debate. The energy transferred by these fields is certainly too weak to ionize molecules or break chemical bonds (Adair 2003).

So called thermal effects on cells, caused by energy transfer, are directly related to the specific absorption rate (SAR) and are well understood. Investigations of athermal cellular effects caused by low intensity exposure, in contrast, have generated conflicting data (Belyaev 2005). This applies to epidemiologic studies and to laboratory 
investigations focusing on cellular effects such as DNA damage or proteome alterations (Blank 2008).

Early epidemiologic studies on mobile phone use did not reveal an associated health risk (Rothman et al. 1996; Valberg 1997). Subsequent studies described some evidence for enhanced cancer risk (Kundi et al. 2004). More recently, an increased brain cancer risk associated with intensive phone use over many years was discussed (Hardell et al. 2008; Hardell et al. 2007; Kan et al. 2008). Sadetzki et al. (2008) reported an exposure-related increase of parotoid gland tumors, which suggests that the possible risk and cellular mechanism is not cell type specific, but may affect various cells.

Repacholi et al. (1997) described an increase in the incidence of lymphoma in sensitized transgenic mice. Their results were, however, not reproduced in follow-up studies (Utteridge et al. 2002). An enhancement of genotoxicity was described (Maes et al. 1996), but again could not be substantiated by the same team (Verschaeve et al. 2006). DNA breaks after RF-EME have been described but could not be reproduced in other laboratories (Diem et al. 2005; Speit et al. 2007).

Several studies have investigated effects of radiation exposure on specific proteins. Thus, Yilmaz et al. (2008), who investigated the effect of RF-EME on the expression level of the anti-apoptotic bcl-2 protein by immunohistochemical staining, reported that exposure to the radiation emitted by a $900-\mathrm{MHz}$ cellular phone for $20 \mathrm{~min}$ did not alter the level of bcl-2 in the brain and testes of rats. Sanchez et al. (2008) investigated the mobile phone radiation-induced stress response in human skin cells after exposure for $2 \mathrm{~h}$ per day and also found no changes. In contrast, in vitro exposure of EAhy926 cells to $900 \mathrm{MHz}$ GSM microwave radiation induced a transient cellular stress response, judged by an increased phosphorylation of heat shock protein-27 (Leszczynski et al. 2002). Results from Nylund and Leszczynski (2004) support the hypothesis that mobile phone radiation can affect the cytoskeleton and the physiological functions that are regulated by the cytoskeleton. More recently, Karinen et al. (2008) provided evidence that mobile phone radiation can alter protein expression in human skin. Blank (2008) has reviewed examples of direct molecular conformation changes caused by radio frequency radiation exposure.

The observed changes in protein phosphorylation are consistent with the activation of a variety of cellular signal transduction pathways by mobile phone radiation, among them the hsp27/p38MAPK stress response (Leszczynski et al. 2002). Friedman et al. (2007) described the rapid activation of ERK (extracellular-signal-regulated kinase), but not of the stress-related MAPKs (mitogen-activated protein kinase) in response to various frequencies and intensities of RF-EME.
The lack of consensus with regard to the difficulty to reproduce effects of RF-EME may to some extent reflect the large number of experimental variables, such as frequency, amplitude, modulation (Litovitz et al. 1990), exposure time and cell types that must be controlled.

In the present study, we measured the impact of RF-EME on the rate of synthesis of a range of proteins. Because any challenge to cells may eventually trigger an adaptive response, the measurement of protein synthesis offers a highly sensitive screening method to detect subtle effects.

The applied methodology was based on metabolic labeling cells during RF exposure and subsequent resolution of protein extracts by two-dimensional electrophoresis in order to measure de novo protein synthesis and total protein amounts (Gerner et al. 2002). To investigate whether or not cell types respond differently, we exposed different kinds of cells including proliferating Jurkat cells, cultured fibroblasts as well as quiescent and inflammatory stimulated primary human white blood cells.

\section{Materials and methods}

\section{Exposure apparatus}

We used the sXc1800 exposure unit (IT'IS, Zürich, Switzerland) to test radio frequency electromagnetic field exposures from mobile communication devices (Schuderer et al. 2004). The unit was installed in a conventional cell incubator with $5 \% \mathrm{CO}_{2}$ and saturated humidity. The exposure unit has two wave guides, which serve as chambers for cell growth and RF exposure. In every experiment, it allows for (and requires the) comparison of control cells and those exposed to modulated GSM $1,800 \mathrm{MHz}$ fields. ELF magnetic fields may actively contribute cellular effects (Mild et al. 2009). However, in our experiments, the background fields were identical between sham and real exposure and therefore cannot be held responsible for the observed differences.

\section{Double-blind experimental design}

Approximately $10 \times 10^{6}$ cells were used for each experiment. Cells were either exposed or mock-exposed to RFEM under blinded conditions, followed by protein extraction and analyses. RF exposure was controlled by a computer program, which switched on the exposure in one waveguide while the other served as exposure control. The exposure settings were recorded in a coded file, and after the biochemical analysis of exposed and control cells, decoding was carried out by a coauthor (HPH) who was not involved in the exposure and biochemical analysis. In this 
manner, we excluded any direct and indirect investigator bias of the results.

\section{Exposure conditions}

In this study, we used modulations closely reflecting the technical specifications of GSM-1800. A GSM signal is modulated, i.e. it has different superordinated structures according to the transmission mode ("GSM-basic" for speech uplink or GSM-DTX for listening). A GSM basic signal is a multi-frame signal consisting of 26 frames, of which every $26^{\text {th }}$ frame is blanked, which creates a low frequency $(8 \mathrm{~Hz})$ component. The GSM-DTX signal consists of periodical single bursts, with some multi-frames interspersed. For details see "www.itis.ethz.ch". A typical phone conversation is a mixture of listening (GSM-DTX) and talking (GSM basic). In the current study, we used a modulation mixture that consisted of about $66 \%$ GSM basic (talking) and 34\% GSM-DTX (listening). The exposure time was $8 \mathrm{~h}$. The intermittence pattern was $5 \mathrm{~min}$. RF exposure "on" and $10 \mathrm{~min}$ "off" (no exposure), to compare the very same conditions, which revealed DNA breaks (Diem et al. 2005; Schwarz et al. 2008). The exposure was $2 \mathrm{~W} / \mathrm{kg}$ during the "on" phase. With the chosen parameters, the controlled temperature difference between the two chambers (control and real exposure) was below $0.15^{\circ} \mathrm{C}$, which, according to our experience, excludes a thermally induced effect in our system (Gerner et al. 2002).

\section{Cell preparation}

Human Jurkat T-cells were cultured in RPMI supplemented with $10 \%$ FCS under standard cell culture conditions. Primary human diploid fibroblasts (ES1 cells) were a kind gift of the workgroup Rüdiger in Vienna. It allowed us to investigate the proteomes of the very same cell line and culture conditions, which upon radiation revealed DNA breaks (Diem et al. 2005; Schwarz et al. 2008). These cells were cultured in Dulbecco`s modified Eagle`s Medium (DMEM, Gibco), 10,000 IU/ml penicillin/streptomycin, $200 \mathrm{mM}$ L-glutamine, $40 \mu \mathrm{g} / \mathrm{ml}$ neomycin and $10 \%$ FCS. Peripheral blood mononuclear cells (white blood cells-WBC) were isolated from heparinized whole blood obtained from healthy donors (mixed with 2 vol. HBSS) by standard density gradient centrifugation with Ficoll-Paque (Pharmacia Biotech). The interface cells were washed and resuspended in autologous (donor) plasma. Inflammatory activation of the cells was accomplished by the addition of $5 \mu \mathrm{g} / \mathrm{mL}$ phytohaemagglutinin (PHA-P; Sigma) and $10 \mathrm{ng} / \mathrm{mL}$ LPS (Sigma).

Cells were metabolically labeled with $0.2 \mathrm{mCi} / \mathrm{mL}$ ${ }^{35} \mathrm{~S}$ protein labeling mix containing ${ }^{35} \mathrm{~S}$-methionine and

${ }^{35}$ S-cysteine (Trans35label, Biomedica, MP Biomedicals) during control exposure and real RF-EME at $37^{\circ} \mathrm{C}$ in a humidified atmosphere containing $5 \% \mathrm{CO}_{2}$. The incubation and labeling times were 2 and $4 \mathrm{~h}$ in exploratory experiments and $8 \mathrm{~h}$ in the final series with three independent repetitions per exposure condition.

\section{Subcellular fractionation}

After incubation and labeling of cells, cytoplasmic proteins were isolated as follows. Cells were lysed in $0.25 \mathrm{M}$ sucrose, $3 \mathrm{mM} \mathrm{MgCl} 2,0.5 \%$ Triton X-100 in lysis buffer (10 mM HEPES/NaOH, pH 7.4, $10 \mathrm{mM} \mathrm{NaCl}, 3 \mathrm{mM}$ $\mathrm{MgCl}_{2}$ ). The cytoplasmic fraction was separated from the nuclei by centrifugation through a $30 \%$ sucrose gradient at $3,500 \mathrm{rpm}$ for $5 \mathrm{~min}$ at $4^{\circ} \mathrm{C}$. After ethanol precipitation, the pelleted cytoplasmic protein fraction was directly solubilized in sample buffer. All buffers used were supplemented with the protease inhibitors PMSF $(1 \mathrm{mM})$, aprotinin, leupeptin and pepstatin A (all at $1 \mu \mathrm{g} / \mathrm{mL}$ ).

\section{D Page}

High-resolution 2D gel electrophoresis was carried out as described previously (Gerner et al. 2002), using the Protean II xi electrophoresis system (Bio-Rad, Hercules, CA). The protein samples were dissolved in sample buffer $(7.5 \mathrm{M}$ urea, 1.5 M Thiourea, 4\% CHAPS, $0.05 \%$ SDS, $100 \mathrm{mM}$ DTT). To optimize the solubilization of proteins, we saturated the protein solution with solid urea. Protein concentrations were determined using a standard Bradford assay.

Solubilized protein $(300 \mu \mathrm{g}$ per gel) was diluted to $280 \mu \mathrm{l}$ with sample buffer freshly adjusted to $0.2 \%$ BioLyte ${ }^{\circledR} 3 / 10$ Ampholytes (Bio-Rad) and 0.002\% bromophenol blue. After $12 \mathrm{~h}$ rehydration of $\mathrm{pH} 5-8,17-\mathrm{cm}$ IPG strips (Bio-Rad, Hercules, CA) at room temperature, IEF of protein samples was performed in a stepwise fashion $(1 \mathrm{~h}$ 0-500 V linear; $5 \mathrm{~h} 500 \mathrm{~V} ; 5 \mathrm{~h} 500-3,500 \mathrm{~V}$ linear; $12 \mathrm{~h}$ $3,500 \mathrm{~V})$. After IEF, the strips were equilibrated with $100 \mathrm{mM}$ DTT and $2.5 \%$ iodacetamide according to the manufacturer's instructions (Bio-Rad Hercules, CA). For SDS-PAGE, focused and equilibrated IPG strips were placed on top of $1.5 \mathrm{~mm} 12 \%$ polyacrylamide slab gels and overlaid with $0.5 \%$ low melting agarose. The gels were run at $15^{\circ} \mathrm{C}$ at $150 \mathrm{~mA}$ for about $4-5 \mathrm{~h}$ and then stained with $400 \mathrm{nM}$ solution of Ruthenium II tris (bathophenanthroline disulfonate; RuBPS) as described by Rabilloud et al. (2001). Fluorescence scanning was performed with a FluorImager 595 (Amersham Biosciences, Amersham, UK) at a resolution of $100 \mu \mathrm{m}$. After scanning, gels were placed on Whatman $3 \mathrm{MM}$ chromatography paper, covered with cling film, and dried at $60^{\circ} \mathrm{C}$ using a slab gel dryer SE110 (Hoefer, San Francisco, CA, USA). Exposure to phosphor storage screens (Molecular Dynamics) was carried out at 
room temperature for $24 \mathrm{~h}$. Screens were subsequently scanned with a Phosphorimager SI (Molecular Dynamics) at a resolution of $100 \mu \mathrm{m}$.

For identification of 2D gel spots, protein samples of unlabeled cells were separated by 2D-PAGE followed by silver staining as described (Gerner et al. 2002).

Gels were warped to a reference gel with the TT900 S2S software (version 2006.0.2389, Nonlinear dynamics, Carlsbad, CA) and evaluated with the Progenesis software PG200 (version 2006, Nonlinear, Newcastle upon Tyne, UK) using the "same spot" algorithm. Spot assignment, background correction, normalization and statistical calculations (analysis of variance, ANOVA) were performed using this software package. Factors indicating up-regulation of proteins in 2D gels were obtained using normalized integrated spot intensities. For most accurate quantification, we only considered spots with an integrated intensity at least three-fold higher than the corresponding spot background value. Integrated intensities from fluorescence detection and autoradiography were normalized against the sum of all matched spots.

\section{Tryptic digestion}

Protein spots were excised, de-stained with $15 \mathrm{mM}$ $\mathrm{K}_{3} \mathrm{Fe}(\mathrm{CN})_{6} / 50 \mathrm{mM} \mathrm{Na}_{2} \mathrm{~S}_{2} \mathrm{O}_{3}$ and extensively washed with a methanol (50\%)/acetic acid (10\%) mixture. The pH was

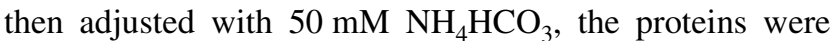
reduced with $10 \mathrm{mM} \mathrm{DTT} / 50 \mathrm{mM} \mathrm{NH} \mathrm{HCO}_{3}$ for $30 \mathrm{~min}$ at $56^{\circ} \mathrm{C}$ and finally alkylated with $50 \mathrm{mM}$ iodacetamide/ $50 \mathrm{mM} \mathrm{NH}_{4} \mathrm{HCO}_{3}$ for $20 \mathrm{~min}$ in the dark. Afterward the gel pieces were dried with acetonitrile and rapidly dried in a vacuum centrifuge (Heto, Denmark). Between each step, the tubes were shaken for 5-10 min (Eppendorf thermomixer Comfort).

The dried gel spots were treated with trypsin $(0.0125 \mathrm{~g} / \mathrm{ml}$; trypsin sequencing grade, Roche Diagnostics, Germany) $/ 50 \mathrm{mM} \mathrm{NH}_{4} \mathrm{HCO}_{3}$, for $20 \mathrm{~min}$ on ice, covered with $50 \mathrm{mM} \mathrm{NH} \mathrm{HCO}_{3}$ and subsequently incubated overnight at $37^{\circ} \mathrm{C}$.

The digested peptides were eluted from the gel spots by addition of $50 \mathrm{mM} \mathrm{NH} \mathrm{NCO}_{3}$ and sonication for $10 \mathrm{~min}$. The supernatants were then transferred to siliconized tubes, and the extraction procedure repeated a further two times with $5 \%$ formic acid $/ 50 \%$ acetonitrile. After this, the extracted peptide solutions were concentrated to a volume appropriate for further analysis.

Mass spectrometry analysis

Proteins were identified by mass spectrometric analysis. Peptides were loaded on a Zorbax 300SB-C8 (5 $\mu \mathrm{m}$,
$0.3 \mathrm{~mm} \times 5 \mathrm{~mm}$ ) column and separated by nanoflow liquid chromatography (1100 Series LC system, Agilent, Palo Alto, CA) using a Zorbax 300SB-C18 $(5 \mu \mathrm{m}, 75 \mu \mathrm{m} \times$ $150 \mathrm{~mm}$ ) column at a flow-rate of $250 \mathrm{nl} / \mathrm{min}$ and using a gradient from $0.2 \%$ formic acid and $3 \%$ acetonitrile to $0.2 \%$ formic acid and $45 \%$ acetonitrile over 12 min. Peptide identification was accomplished by MS/MS fragmentation analysis with an ion trap mass spectrometer (XCT-Ultra, Agilent) equipped with an orthogonal nanospray ion source. The MS/MS data were interpreted by the Spectrum Mill MS Proteomics Workbench software (Version A.03.03, Agilent) and searched against the SwissProt Database version 20061207 allowing the initial search algorithm a precursor mass deviation of $1.5 \mathrm{Da}$, a product mass tolerance of $0.7 \mathrm{Da}$ and a minimum matched peak intensity (\%SPI) of $70 \%$. Due to previous chemical modification, carbamidomethylation of cysteines was set as fixed modification. No other modifications were considered here. Peptide scores were essentially calculated from sequence tag lengths, but also considered mass deviations. To assess the reliability of the peptide scores, we performed searches against the corresponding reverse database. $6.0 \%$ positive hits were found with peptides scoring $>9.0$, while no positive hits were found with peptides scoring $>13.0$. All spots were identified with at least two different peptides including one scoring at least higher than 13.0. The details of protein identifications, including peptide sequences, peptide scores and sequence coverage are provided in the electronic supplementary data.

\section{Statistical analysis}

In each experiment, we compared proteins from cells kept under identical culture conditions. The only difference was that they were exposed under sham or real conditions. The gel from sham exposed cells (reference) was compared to the gel from the cells with real exposure, using the TT900 S2S software (version 2006.0.2389, Nonlinear dynamics, Carlsbad, CA) and then evaluated with the Progenesis software PG200 (version 2006, Nonlinear) using the "same spot" algorithm. Spot assignment, background correction, normalization and statistical calculations (one way analysis of variance, ANOVA, calculated from three independent experimental replicates per group) were performed using this software package. If the " $P$-value" for a protein was $\geq 0.05$, this was considered "not significant".

For each data set (cell type), in each table, we summarized three independent experiments (pairs of sham and real exposed cells), where the differences between sham and real exposure are expressed as average "increase factor" ( $\mathrm{x}$-fold higher) in real exposed cells. 

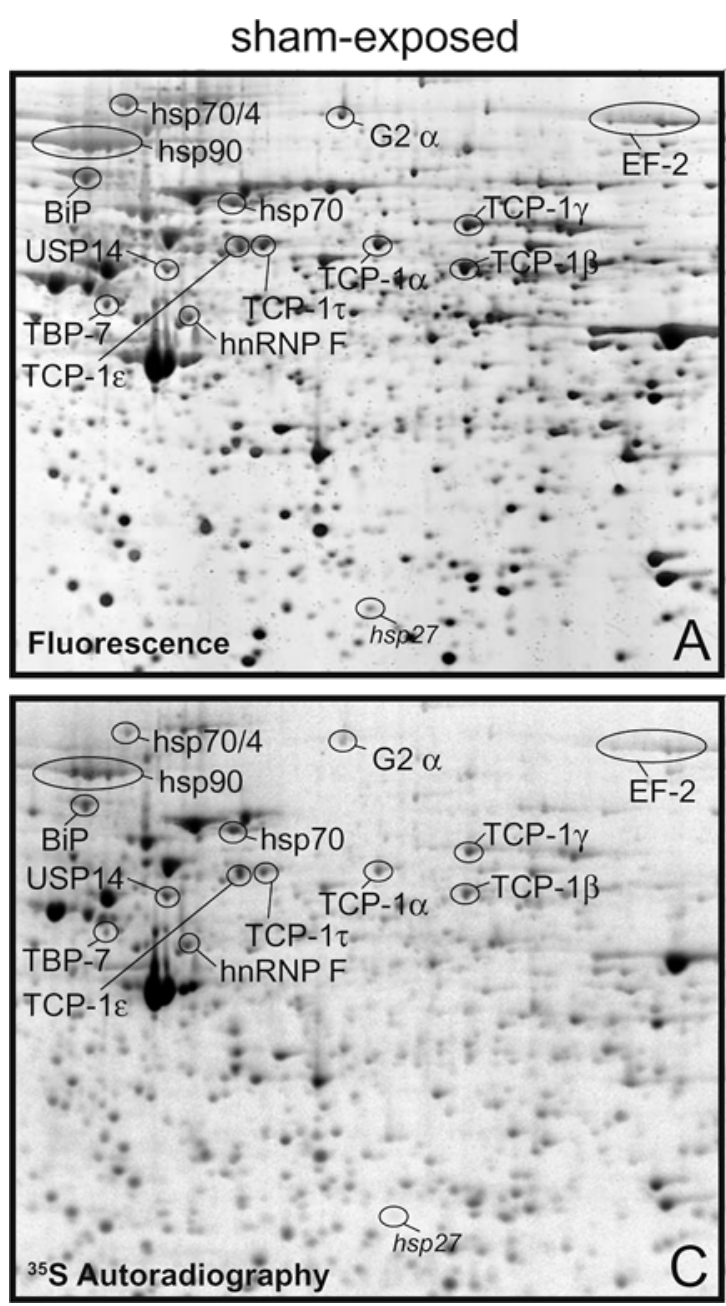

Fig. 1 RF-EME exposure of Jurkat T-cells generally increased ${ }^{35} \mathrm{~S}$ incorporation rates, indicating induction of protein synthesis. The cells (exposed and controls) were metabolically labeled for $8 \mathrm{~h}$ during exposure. a, b Fluorescence detection of protein amounts, separated by 2D-

\section{Results}

Jurkat cells

Figure 1 shows corresponding 2D gels derived from exposed and control cells. The separated proteins were quantified for protein amounts (fluorescence detection) and protein synthesis $\left({ }^{35} \mathrm{~S}\right.$-autoradiography). The spot pattern obtained was very highly reproducible: 855 spots were consistently detected in six gels from three independent experiments, each with exposed and corresponding control cells. The average standard deviation of fluorescence spot intensities $(18.8 \%)$ was determined from the three independent control cell gels. Fluorescence spot intensities for some individual proteins appeared to reveal an increased level in response to RF-EME. Application of strict spot quantification criteria, however, indicated that there were no significant differences between RF-EME-exposed and control
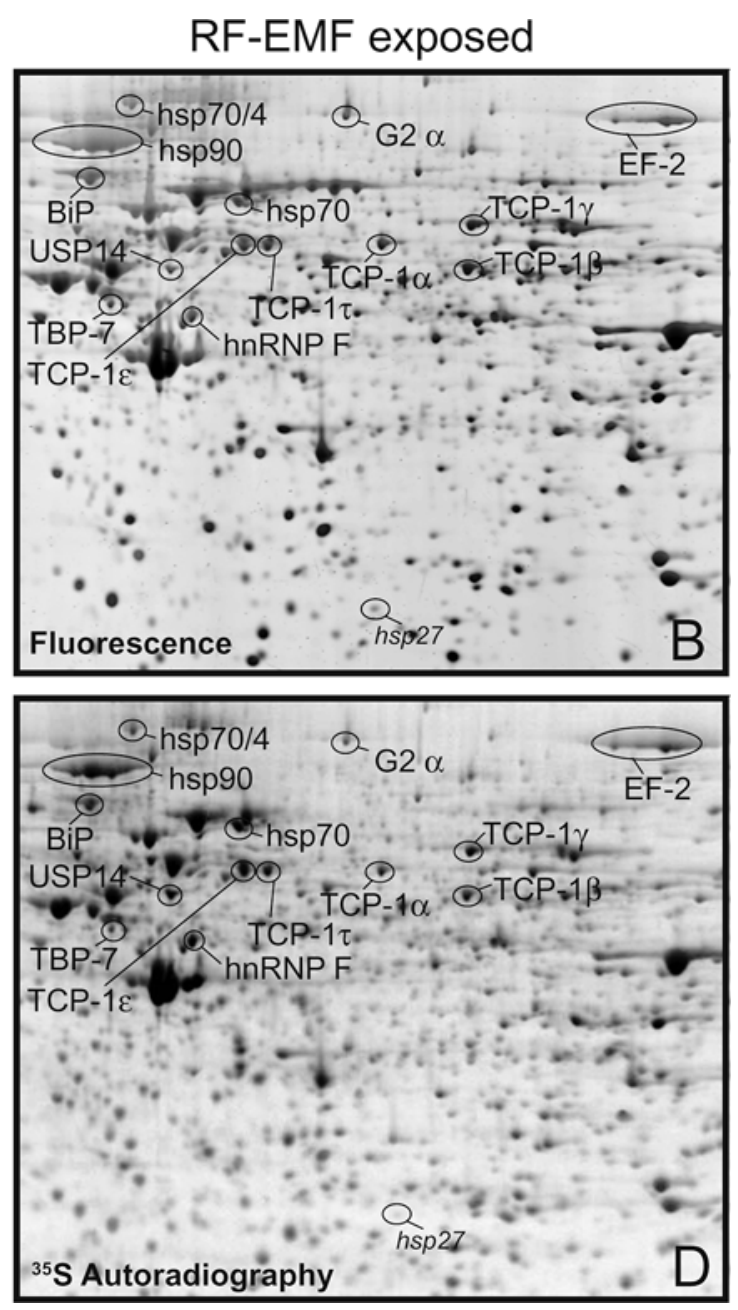

PAGE. c, $\mathbf{d}$ De novo synthesis $\left({ }^{35} \mathrm{~S}\right.$ autoradiographs) of proteins depicted in $\mathbf{a}$ and $\mathbf{b}$, respectively. While protein amounts did not show significant alterations, protein synthesis was generally increased due to RF-EME. Annotated proteins are further detailed in Table 1

cells. Autoradiographs of the same gels, however, revealed significant differences in the rate of de novo synthesis of several proteins (greater than 2 fold) between RF-EME and control cells. Figure 1c, d shows the higher general autoradiograph intensity observed for radiation exposed cells. On average, the total ${ }^{35} \mathrm{~S}$ autoradiograph intensity was almost doubled [the measured increase was $93 \pm 28 \%(n=3)$ ]. Actually all detectable protein spots displayed an increased ${ }^{35} \mathrm{~S}$ incorporation rate.

We categorized a protein as specifically up-regulated if the normalized integrated ${ }^{35} \mathrm{~S}$ autoradiograph spot intensity was at least two-fold greater than the corresponding control cell spot with an ANOVA $P$-value of less than 0.05 . Using this criterion, fourteen proteins were found to be specifically up-regulated and were subsequently identified by mass spectrometry as described in Materials and Methods (Table 1 and supplementary data). Figure 2 provides three examples of proteins specifically up-regulated by RF-EME: 


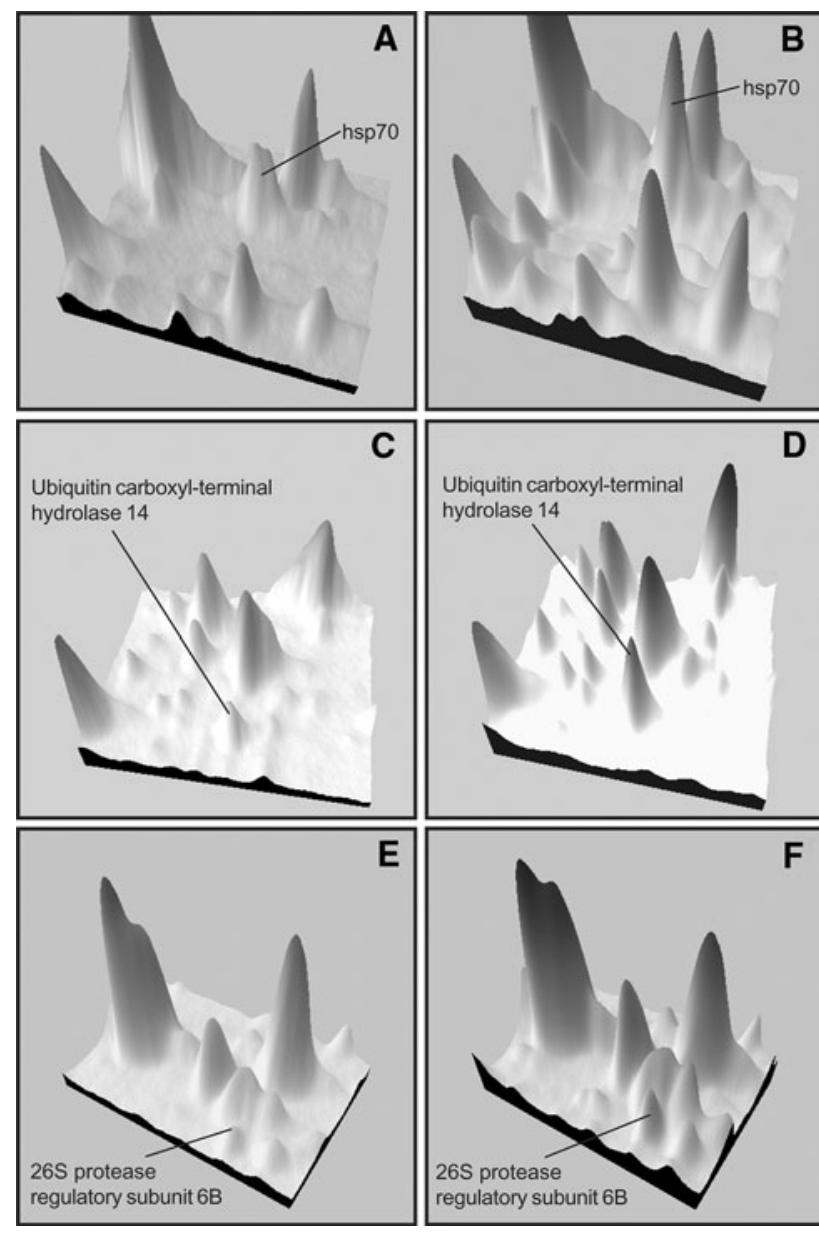

Fig. 2 3D-landscapes of selected gel areas. Relative spot intensities from controls (a, c, e) and RF-EME exposed cells $(\mathbf{b}, \mathbf{d}, \mathbf{f})$ are depicted as spot heights to demonstrate the specific induction of some proteins relative to the local spot environment. The indicated proteins are also listed in Table 1

heat shock protein 70 , ubiquitin carboxyl-terminal hydrolase 14 and $26 \mathrm{~S}$ protease regulatory subunit $6 \mathrm{~B}$. Figure 3 shows peptide fragmentation mass spectra of peptides derived from ubiquitin carboxyl-terminal hydrolase 14 and $26 \mathrm{~S}$ protease regulatory subunit 6 in order to demonstrate the high degree of reliability of the protein identification procedure used. The RF-EME induced increase in protein synthesis (Fig. 4a-f) was highly reproducible.

\section{Fibroblasts}

Cultured human fibroblasts showed the highest level of responsiveness to RF-EME (Fig. 4e, f; Table 2) with an average protein synthesis increase of $128 \pm 22 \%$ (three independent experiments). Thirteen of the fourteen proteins whose rate of de novo synthesis was increased in Jurkat cells were also synthesized at a higher rate in fibroblasts. As well as these, the rates of synthesis of annexin A1 and A5 were found to be significantly increased (Table 2). This finding suggests that the proteome alterations in responsive cells induced by RF-EME exposure are characteristic for this kind of cell stress.

White blood cells

Primary mononuclear cells isolated from peripheral blood (white blood cells, WBC) responded only marginally to RF-EME (Fig. 4g, h; Table 3). The apparent increase in ${ }^{35} \mathrm{~S}$ incorporation was less than $10 \%$, which is within the margin of error of the applied methodology. Inflammatory stimulation of WBCs by treatment with lipopolysaccharide and phytohaemagglutinin increased the level of protein synthesis by these cells (compare Fig. 4g-i), which is consistent with the induction of cell proliferation as previously described in more detail (Traxler et al. 2004). Notably, RFEME further increased the level of ${ }^{35} \mathrm{~S}$ incorporation by the stimulated cells (compare Fig. $4 \mathbf{i}-\mathbf{j}$ ) by an average of $43 \pm 13 \%$ (three independent experiments with three different donors). The proteome alterations were, however, less compared to those observed in Jurkat cells and fibroblasts. Only one protein, hsp60, was induced more than two-fold (Table 4).

\section{Discussion}

We used a highly sensitive method of measuring protein synthesis rates and protein amounts to investigate the potential effects of low-intensity mobile phone radiation exposure on cells. Our results show that the rate of protein synthesis in proliferating cells is increased by long-term (8 h) RF-EME, while no effect was detectable in quiescent white blood cells treated in the same manner. Although the observed changes reached no statistical significance at short exposure times, we observed some trends consistent with but also extend observations made by Nylund and Leszczynski (2004), who used the same exposure system, but only measured protein amounts (and not de novo synthesis).

Usefully, our results appear to reconcile a number of conflicting previous findings. First, we found both RF-EME responsive and RF-EME-insensitive cells (compare Tables 1, 2 with Table 3). The RF-EME insensitive quiescent WBCs (Table 3) were rendered sensitive to RF-EME by inflammatory activation (Fig. 4). Inflammatory activation of WBC induces T-cell proliferation and consequently an increased rate of protein synthesis (Traxler et al. 2004). Thus, our data suggest that proliferating cells with high protein synthesis rates are more sensitive to RF-EME than cells with lower protein production. Many studies have been performed with quiescent white blood cells, which were also insensitive under our experimental conditions. 
Fig. 3 Identification details of isolated 2D gel spots. After tryptic digestion and peptide separation by nano-flow liquid chromatography, isolated peptides were fragmented in an ion trap mass spectrometer. a-c Peptides identified in the spot identified as ubiquitin carboxylterminal hydrolase 14 ( $z$, peptide charge; Score, Spectrum Mill peptide score; SPI, scored peak intensity). b Assignment of identified peptides to protein sequence. c MS2 spectrum of the peptide AQLFALTGVQPAR. d-f Peptides identified in the spot identified as $26 \mathrm{~S}$ protease regulatory subunit $6 \mathrm{~B}$, e assignment of identified peptides to protein sequence, $\mathbf{f}$ MS2 spectrum of the peptide ENAPAIIFIDEIDAIATK

\begin{tabular}{|c|c|c|c|c|c|c|}
\hline $\mathrm{z}$ & Score & $\begin{array}{l}\text { SPI } \\
(\%)\end{array}$ & $\begin{array}{l}\text { Spectrum } \\
\text { Intensity }\end{array}$ & Sequence & $\begin{array}{c}\mathrm{MH}^{+} \\
\text {Matched } \\
\text { (Da) }\end{array}$ & \\
\hline 2 & 17.66 & 95.2 & $5.74 \mathrm{e}+008$ & (K) AQLFALTGVQPAR (Q) & 1371.774 & \\
\hline 3 & 15.92 & $\underline{84.4}$ & $2.41 \mathrm{e}+007$ & (R) LEAIEDDSVKETDSSSASAATPSKK (K) & 2566.237 & \\
\hline 2 & 13.18 & 84.0 & $5.58 \mathrm{e}+007$ & (R) RVE TMEEESEQ $(-)$ & 1378.616 & A \\
\hline 2 & 12.11 & 77.0 & $4.28 \mathrm{e}+008$ & (R) LPAYLIIQMVR (F) & 1304.739 & A \\
\hline
\end{tabular}

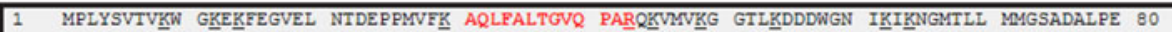
81 EPSAKTVFVE DMTEEQLASA MELPCGLTNL GNTCMNATV QCIRSVPELR DALKRYAGAL RASGEMASAQ YITAALRDLF 160 161 DSMDKKTSSI PPIILLQFLH MAFPQFAEKG EQGQYLQQDA NECWIQMMRV LQQKLLEAIBD DSVKETDSSS ASAATPSKKKK 240

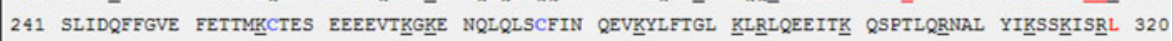

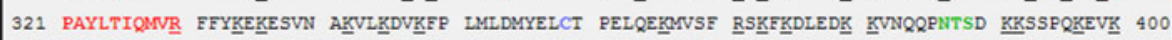
401 YEPFSFADDI GSNNCGYYL QAVLTHQGRS SSSGHYVSWV KRRQDEWIKF DDDKVSIVTP EDILRLSGGG DWHIAYVLLY 480 481 GPRRVETMEE ESEQ

The matched peptides cover $12 \%$ (60/494 AA's) of the protein.

Protein Name: Ubiquitin carboxyl-terminal hydrolase 14 - Homo sapiens (Human)

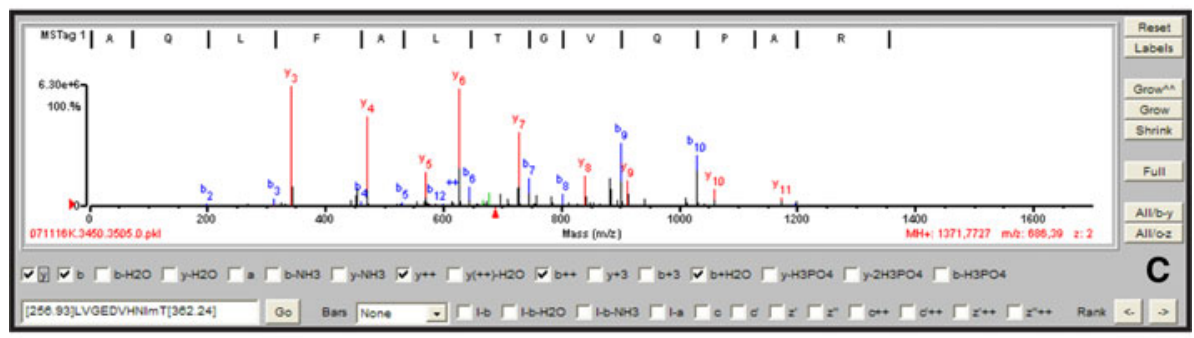

\begin{tabular}{|c|c|c|c|c|c|c|}
\hline $\mathbf{z}$ & Score & $\begin{array}{l}\text { SPI } \\
\text { (\%) }\end{array}$ & $\begin{array}{l}\text { Spectrum } \\
\text { Intensity }\end{array}$ & Sequence & $\begin{array}{c}\mathrm{MH}^{+} \\
\text {Matched } \\
\text { (Da) }\end{array}$ & \multirow{5}{*}{ D } \\
\hline 3 & 22.00 & $\underline{100.0}$ & $8.36 e+007$ & (K) ENAPAIIFIDEIDAIATK (R) & 1944.032 & \\
\hline 3 & 15.14 & $\underline{97.0}$ & $1.49 \mathrm{e}+008$ & (K) ENAPAIIFIDEIDAIATKR (F) & 2100.133 & \\
\hline 3 & 13.23 & $\underline{76.8}$ & $3.41 \mathrm{e}+008$ & (R) ILLELLNQMDGFDQNVNVK (V) & 2203.143 & \\
\hline 3 & 12.74 & $\underline{73.9}$ & $8.17 e+007$ & (K) ENAPAIIFIDEIDAIATK (R) & 1944.032 & \\
\hline
\end{tabular}

1 MEEIGILVER AQDEIPALSV SRPQTGLSFL GPEPEDLEDL YSRYKKLQQE LEFLEVQEEY IKDEQKNNLKR EFLHAQEEVR 80 81 RIQSIPLVIG QFLEAVDQNT AIVGSTTGSN YYVRILSTID RELLKPNASV ALHKHSNALV DVLPPEADSS TMMLTSDQKP 160

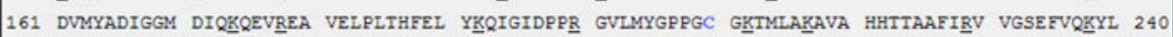
241 GEGPRMVRDV FRLAKENAPA IIFIDEIDAI ATKRFDAQTG ADREVQRILL ELLNQMDGFD QNVNVIKVIMA TNRADTLDPA 320 321 LLRPGRLDRK IEFPLPDRRQ KRLIFSTITS KMMNLEEVDL EDYVARPDKI SGADINSICQ ESGMLAVREN RYIVLARDFE 400 401 KAYKKTVIKKD EQEHEFY즌

he matched peptides cover $8 \%$ (37/418 AA's) of the protein.

Brotein Name: 26 S protease regulatory subunit 6 B. Homo sapiens/Human)

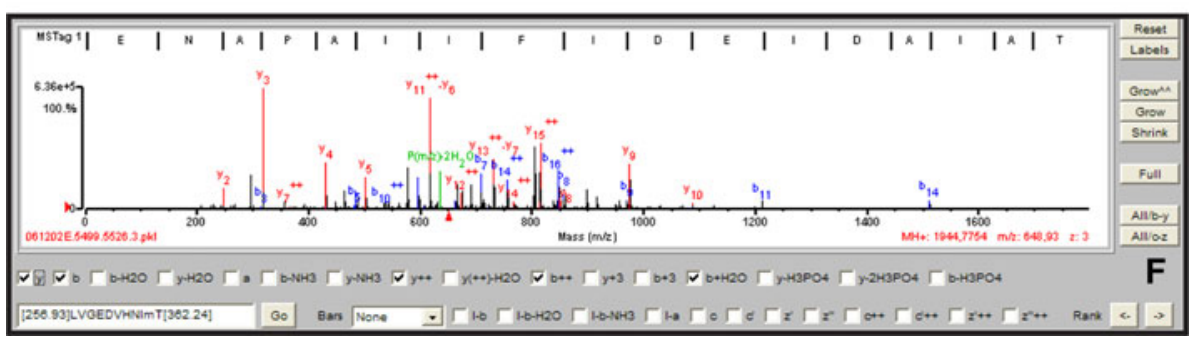

Second, the exposure time seems to be a critical factor. In our preliminary experiments, we did not observe significant effects with 2 and 4 h exposure times (data not shown). An 8-h exposure was required to obtain reproducible and significant effects, a time much longer than the longest exposure time used in most other studies. Third, the determination of protein amounts by spot integration is not very precise. Silver staining in particular, does not produce reliable quantitative data (White et al. 2004). Standard deviations obtained with the much more accurate fluores- cence detection methods are usually of the order of $25 \%$. Consequently, subtle alterations may easily be missed due to limited sensitivity.

Possible mechanisms

During electromagnetic exposure, we applied $5 \mathrm{~min}$ of "exposure on" and 10 min of "off" on the same cell types and/ or conditions, which revealed DNA breaks (Diem et al. 2005; Franzellitti et al. 2010; Schwarz et al. 2008). Interestingly, 
Fig. 4 The RF-EME induced increase of ${ }^{35} \mathrm{~S}$ incorporation rates was reproducibly observed in different cell types. $\mathbf{a} \mathbf{b}$ and $\mathbf{c}$, d show two independent experiments with Jurkat cells. e, $\mathbf{f}$ is a representative example for cultured human fibroblasts showing the highest induction of ${ }^{35} \mathrm{~S}$ incorporation rates by RF-EME, $\mathbf{g}, \mathbf{h}$ shows a representative example of quiescent (metabolically inactive) primary human white blood cells (WBC). Here, RF-EME hardly induced detectable increases in ${ }^{35} \mathrm{~S}$ incorporation rates; compared to untreated controls (g), activated WBC (i) displayed higher ${ }^{35} \mathrm{~S}$ incorporation rates, RF-EME induced a further increase in ${ }^{35} \mathrm{~S}$ incorporation rates $(\mathbf{j})$, which indicates that activity renders cells sensitive to RF-EME
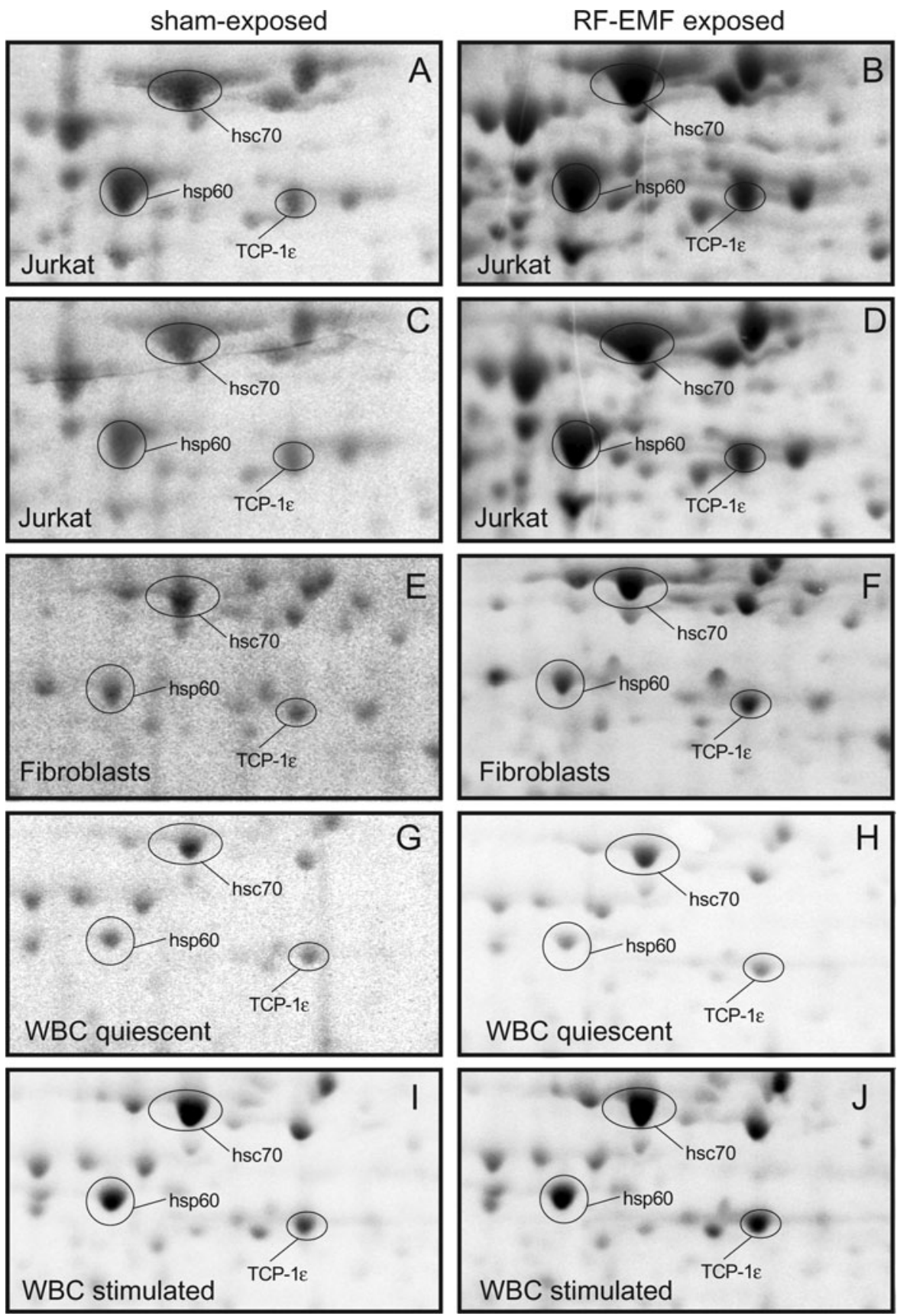

we found the same cells reactive (e.g. fibroblasts, Table 2) or nonreactive (e.g. naïve lymphocytes, Table 3), when investigating protein synthesis. This may suggest a common underlying mechanism between DNA breaks and increased protein synthesis in reactive cells.

With this exposure regime, the temperature difference between exposed cells and control cells was less than $0.15^{\circ} \mathrm{C}$, we exclude a heat-related response. Heat-induced proteome alterations detectable with our proteome profiling methodology would require temperature differences greater than $1^{\circ} \mathrm{C}$. Furthermore, a temperature increase of even $1^{\circ} \mathrm{C}$ does not affect e.g. TCP-1 family members (Gerner et al.
2002). We conclude that the warming of the cell cultures caused by RF exposure was too low to account for the present observations.

Most of the proteins found to be induced by RF-EME are chaperones, which are mediators of protein folding. Since the applied electromagnetic fields were very weak, the direct and active denaturation of existing proteins by RF-EME exposure appears unlikely to underlie the observed increased level of protein synthesis. Resonance phenomena may concentrate radiation exposure-mediated physical energy on hot spots and have already been suggested to cause biological effects (Belyaev 2005). Indeed, exposure to 
Table 1 Jurkat cells: proteins displaying a specific up-regulation of ${ }^{35} \mathrm{~S}$ incorporation by real exposure

\begin{tabular}{|c|c|c|c|c|}
\hline Acc-no & Protein name & Abbreviations & Increase factor & $\operatorname{ANOVA}(P)$ \\
\hline P43686 & $26 \mathrm{~S}$ protease regulatory subunit $6 \mathrm{~B}$ & TBP-7 & 2.6 & $<0.001$ \\
\hline P11021 & 78-kDa glucose-regulated protein & $\mathrm{BiP}$ & 2.5 & 0.005 \\
\hline P13639 & Elongation factor 2 & $\mathrm{EF}-2$ & 4.4 & 0.017 \\
\hline P10809 & 60-kDa heat-shock protein, mitochondrial & hsp60 & 1.4 & $>0.05$ \\
\hline P08107 & Heat-shock 70-kDa protein 1 & hsp70 & 2.4 & 0.004 \\
\hline P43932 & Heat-shock 70-kDa protein 4 & hsp70/4 & 4.0 & $<0.001$ \\
\hline P08238 & Heat-shock protein 90 & hsp90 & 2.4 & $<0.001$ \\
\hline P52597 & Heterogeneous nuclear ribonucleoprotein $\mathrm{F}$ & hnRNP F & 3.5 & 0.004 \\
\hline Q14697 & Neutral alpha-glucosidase AB & $\mathrm{G} 2 \alpha$ & 3.5 & $<0.001$ \\
\hline P17987 & T-complex protein 1 , alpha subunit & TCP- $1 \alpha$ & 2.8 & 0.001 \\
\hline P78371 & T-complex protein 1 , beta subunit & TCP- $1 \beta$ & 2.3 & 0.026 \\
\hline P48643 & T-complex protein 1 , epsilon subunit & ТCP- $1 \varepsilon$ & 2.6 & 0.002 \\
\hline P49368 & T-complex protein 1, gamma subunit & TCP-1 $1 \gamma$ & 2.4 & 0.033 \\
\hline P50990 & T-complex protein 1 , theta subunit & TCP- $1 \tau$ & 2.9 & 0.001 \\
\hline P54578 & Ubiquitin carboxyl-terminal hydrolase 14 & USP14 & 3.5 & $<0.001$ \\
\hline P04083 & Annexin A1 & A-I & 1.5 & 0.031 \\
\hline P08758 & Annexin A5 & $A-V$ & 1.2 & $>0.05$ \\
\hline
\end{tabular}

Proteins are depicted in Fig. 1 and annotated with the listed abbreviations. The increase factor and the ANOVA $P$-values are derived from three independent experimental replicates to compare spot intensities from RF-EMF exposed cells and controls. Proteins printed in italics did not show relevant alterations. They are listed to be complete in comparison with the other cell types analyzed (Tables 2-4). Accession numbers and protein names are according to the SwissProt database. Details of mass analysis results are provided electronically in the supplementary data

Table 2 Protein alterations detected in fibroblasts, legend as in Table 1

\begin{tabular}{|c|c|c|c|c|}
\hline Acc-no & Protein name & Abbreviations & Increase factor & ANOVA $(P)$ \\
\hline P43686 & $26 \mathrm{~S}$ protease regulatory subunit $6 \mathrm{~B}$ & TBP-7 & 2.5 & $<0.001$ \\
\hline P11021 & 78-kDa glucose-regulated protein & $\mathrm{BiP}$ & 3.5 & $<0.001$ \\
\hline P13639 & Elongation factor 2 & $\mathrm{EF}-2$ & 2.2 & 0.033 \\
\hline P10809 & 60-kDa heat-shock protein, mitochondrial & hsp60 & 2.3 & $>0.05$ \\
\hline P08107 & Heat-shock 70-kDa protein 1 & hsp70 & 4.7 & $<0.001$ \\
\hline P43932 & Heat-shock 70-kDa protein 4 & hsp70/4 & 4.7 & $<0.001$ \\
\hline P08238 & Heat-shock protein 90 & hsp90 & 2.6 & 0.023 \\
\hline P52597 & Heterogeneous nuclear ribonucleoprotein $\mathrm{F}$ & hnRNP F & 2.5 & 0.02 \\
\hline Q14697 & Neutral alpha-glucosidase $\mathrm{AB}$ & $\mathrm{G} 2 \alpha$ & 3.1 & 0.011 \\
\hline P17987 & T-complex protein 1 , alpha subunit & $T C P-1 \alpha$ & 1.8 & 0.043 \\
\hline P78371 & T-complex protein 1 , beta subunit & ТCР- $1 \beta$ & 2.3 & 0.007 \\
\hline P48643 & T-complex protein 1 , epsilon subunit & TCP-1 $1 \varepsilon$ & 4.7 & $<0.001$ \\
\hline P49368 & T-complex protein 1, gamma subunit & $\mathrm{TCP}-1 \gamma$ & 2.5 & 0.042 \\
\hline P50990 & T-complex protein 1 , theta subunit & TCP- $1 \tau$ & 2.6 & 0.011 \\
\hline P54578 & Ubiquitin carboxyl-terminal hydrolase 14 & USP14 & 2.5 & $<0.001$ \\
\hline P04083 & Annexin A1 & A-I & 2.4 & $<0.001$ \\
\hline P08758 & Annexin A5 & A-V & 2.7 & $<0.001$ \\
\hline
\end{tabular}

low frequency electromagnetic fields caused effects, which were reduced by noise signals (Litovitz et al. 1997), providing further support for the concept of resonance as an underlying condition. Hydrogen bonds are known to resonate with microwaves. Folding of newly synthesized proteins in the endoplasmic reticulum occurs via a process involving the formation of intermediate folded structures (Arai and Kuwajima 2000) mediated by several chaperones (Deuerling and Bukau 2004). This process could potentially respond in a very sensitive fashion to radiation-induced excitation of hydrogen bonds as this could cause a temporary disturbance of spatial orientation. An increased rate of 
Table 3 WBC quiescent: for legend see Table 1

\begin{tabular}{|c|c|c|c|c|}
\hline Acc-no & Protein name & Abbreviations & Increase factor & $\operatorname{ANOVA}(P)$ \\
\hline P43686 & $26 S$ protease regulatory subunit $6 B$ & $T B P-7$ & 1.2 & $>0.05$ \\
\hline$P 11021$ & 78-kDa glucose-regulated protein & BiP & 1.1 & $>0.05$ \\
\hline P13639 & Elongation factor 2 & $E F-2$ & 1.3 & $>0.05$ \\
\hline P10809 & 60-kDa heat shock protein, mitochondrial & hsp60 & 1.1 & $>0.05$ \\
\hline P08107 & Heat-shock 70-kDa protein 1 & hsp70 & 1.0 & 0.040 \\
\hline P43932 & Heat-shock $70-k D a$ protein 4 & hsp 70/4 & 1.1 & $>0.05$ \\
\hline P08238 & Heat-shock protein 90 & hsp90 & 0.8 & $>0.05$ \\
\hline P52597 & Heterogenеous nuclear ribonucleoprotein $F$ & $h n R N P F$ & 1.0 & $>0.05$ \\
\hline$Q 14697$ & Neutral alpha-glucosidase $A B$ & $G 2 \alpha$ & nd & $n d$ \\
\hline P17987 & T-complex protein 1 , alpha subunit & TCP- $1 \alpha$ & 1.0 & 0.037 \\
\hline P78371 & T-complex protein 1 , beta subunit & TCP- $1 \beta$ & 1.0 & 0.023 \\
\hline P48643 & T-complex protein 1, epsilon subunit & TCP-1 $1 \varepsilon$ & 1.2 & $<0.001$ \\
\hline P49368 & T-complex protein 1 , gamma subunit & $T C P-1 \gamma$ & 1.0 & $>0.05$ \\
\hline P50990 & T-complex protein 1 , theta subunit & $T C P-1 \tau$ & 1.1 & $>0.05$ \\
\hline P54578 & Ubiquitin carboxyl-terminal hydrolase 14 & USP14 & 1.2 & $>0.05$ \\
\hline P04083 & Annexin Al & $A-I$ & 0.9 & $>0.05$ \\
\hline P08758 & Annexin A5 & $A-V$ & 0.8 & $>0.05$ \\
\hline
\end{tabular}

Table 4 WBC stimulated: for legend see Table 1

\begin{tabular}{|c|c|c|c|c|}
\hline Acc-no & Protein name & Abbreviations & Increase factor & ANOVA $(P f)$ \\
\hline P43686 & $26 S$ protease regulatory subunit $6 B$ & $T B P-7$ & 1.2 & $>0.05$ \\
\hline$P 11021$ & 78-kDa glucose-regulated protein & BiP & 1.1 & $>0.05$ \\
\hline P13639 & Elongation factor 2 & $E F-2$ & 1.0 & $>0.05$ \\
\hline P10809 & $60-\mathrm{kDa}$ heat-shock protein, mitochondrial & hsp60 & 2.7 & $<0.001$ \\
\hline P08107 & Heat-shock $70-\mathrm{kDa}$ protein 1 & hsp70 & 1.5 & 0.031 \\
\hline P43932 & Heat-shock 70-kDa protein 4 & hsp $70 / 4$ & 0.9 & $>0.05$ \\
\hline P08238 & Heat-shock protein 90 & hsp90 & 0.9 & $>0.05$ \\
\hline P52597 & Heterogeneous nuclear ribonucleoprotein $F$ & hnRNP F & 1.2 & $>0.05$ \\
\hline$Q 14697$ & Neutral alpha-glucosidase $A B$ & $G 2 \propto$ & $n d$ & nd \\
\hline P17987 & T-complex protein 1 , alpha subunit & TCP- $1 \alpha$ & 1.3 & 0.037 \\
\hline P78371 & T-complex protein 1 , beta subunit & TCP-1 $\beta$ & 1.3 & 0.023 \\
\hline P48643 & T-complex protein 1 , epsilon subunit & TCP- $1 \varepsilon$ & 1.5 & $<0.001$ \\
\hline P49368 & T-complex protein 1, gamma subunit & $T C P-1 \gamma$ & 1.0 & $>0.05$ \\
\hline P50990 & $T$-complex protein 1, theta subunit & $T C P-1 \tau$ & 1.0 & $>0.05$ \\
\hline P54578 & Ubiquitin carboxyl-terminal hydrolase 14 & USP14 & 1.0 & $>0.05$ \\
\hline P04083 & Annexin Al & $A-I$ & 1.1 & $>0.05$ \\
\hline P08758 & Annexin A5 & $A-V$ & 1.2 & $>0.05$ \\
\hline
\end{tabular}

inappropriate folding of newly synthesized proteins would not affect existing proteins and thus render cell function intact for some time (unless key labile proteins are affected). Furthermore, such a mechanism would not necessarily have a significant impact on total protein amounts. However, later on it would increase the protein synthesis rate in response to an increased rate of turnover of the newly folded proteins. This interpretation plausibly explains the reported increased level of protein synthesis.
Essentially all detectable proteins displayed an increased synthesis rate, which indicates a general compensatory response, e.g. to a hampered supply of functional proteins. Proteins with the highest response (Tables 1, 2) are involved in the chaperoning of newly synthesized proteins and protein turnover. Chaperones such as $78-\mathrm{kDa}$ glucoseregulated protein, heat-shock proteins and T-complex protein 1 family members are directly involved in protein folding and assist folding of newly synthesized proteins 
(Deuerling and Bukau 2004). Neutral alpha-glucosidase $\mathrm{AB}$ is an important endoplasmic reticulum protein responsible for quality control and glycoprotein processing (Ellgaard and Helenius 2003). Ubiquitin carboxyl-terminal hydrolase 14 , also termed deubiquitinating enzyme 14 , is required for proteasomal processing of ubiquitinated substrates (Koulich et al. 2008). The 26S protease regulatory subunit 6B is also involved in ATP-dependent degradation of ubiquitinated proteins and in transcriptional regulation (Choi et al. 1996). Elongation factor 2 is actually indispensable for protein synthesis (Perentesis et al. 1992).

\section{Exposure time matters}

Our data complement those of Lee et al. (2006) who did not find changes in the expression levels of HSP90, HSP70, and HSP27, or MAPK phosphorylation in Jurkat cells exposed to RF-EM for $30 \mathrm{~min}$ and $1 \mathrm{~h}$. In our experiments, increased protein synthesis was only observed after an 8-h exposure time and was in fact fully reversible within $2 \mathrm{~h}$ (data not shown). This is also in agreement with Sanchez et al. (2008) and Yilmaz et al. (2008) who found no changes associated with exposure times of $2 \mathrm{~h}$ and $20 \mathrm{~min}$, respectively, i.e. changes in the rate of protein synthesis are induced by long exposures to low intensity RF-EM.

\section{Conclusions}

Our data describe cell responses to RF-EME exposure specifically observed in actively proliferating cells. When investigating protein synthesis, we found the same cell types nonreactive or reactive, compared to those to reveal DNA breaks (Diem et al. 2005; Schwarz et al. 2008). Active cells continuously repair DNA-damage as it occurs as side product of DNA transcription or respiratory chain products (Alberts et al. 2001; Branden and Tooze 1999). Therefore, a subtle inhibition of any part of the antioxidant protection or the DNA repair system would accumulate damaged DNA. Consequently, interference with protein expression may explain the DNA changes found by others (Belyaev et al. 2005; Diem et al. 2002; Schwarz et al. 2008) as indicator for a risk associated with long-term exposure.

The observed proteome alterations support a novel mechanistic model for the understanding of RF-EME induced bioeffects: this model is based on radiation-induced disturbances of hydrogen bonds, which may be essential during the protein folding process. Our results do not directly indicate a health risk. However, the finding that metabolically active and/or proliferating cells are more responsive to RF-EME implies a higher sensitivity of growing organisms.
Acknowledgments The investigations were generously funded by the Austrian workers compensation board, within a project of the ATHEM research programme. We thank Elisabeth Traxler for her contribution to the cell culture and laboratory work and her contagious good moods.

\section{Conflict of interest statement None.}

Open Access This article is distributed under the terms of the Creative Commons Attribution Noncommercial License which permits any noncommercial use, distribution, and reproduction in any medium, provided the original author(s) and source are credited.

\section{References}

Adair RK (2003) Biophysical limits on athermal effects of RF and microwave radiation 2. Bioelectromagnetics 24:39-48

Alberts B, Johnson A, Lewis J, Raff M, Roberts K, Walter P (2001) Molecular biology of the cell. Garland Science Textbooks, New York

Arai M, Kuwajima K (2000) Role of the molten globule state in protein folding. Adv Protein Chem 53:209-282

Belyaev IY (2005) Non-thermal biological effects of microwaves. Microw Rev 11:13-29

Belyaev IY, Hillert L, Protopopova M, Tamm C, Malmgren LO, Persson BR et al (2005) $915 \mathrm{MHz}$ microwaves and $50 \mathrm{~Hz}$ magnetic field affect chromatin conformation and 53BP1 foci in human lymphocytes from hypersensitive and healthy persons. Bioelectromagnetics 26:173-184

Blank M (2008) Protein and DNA reactions stimulated by electromagnetic fields. Electromagn Biol Med 27:3-23

Branden C, Tooze J (1999) Introduction to protein structure. Garland Science Textbooks, Ney York and Oxford

Choi HS, Seol W, Moore DD (1996) A component of the 26S proteasome binds on orphan member of the nuclear hormone receptor superfamily. J Steroid Biochem Mol Biol 56:23-30

Deuerling E, Bukau B (2004) Chaperone-assisted folding of newly synthesized proteins in the cytosol. Crit Rev Biochem Mol Biol 39:261-277

Diem E, Ivancsits S, Rudiger HW (2002) Basal levels of DNA strand breaks in human leukocytes determined by comet assay. J Toxicol Environ Health A 65:641-648

Diem E, Schwarz C, Adlkofer F, Jahn O, Rüdiger H (2005) Non-thermal DNA breakage by mobile-phone radiation $(1800 \mathrm{MHz})$ in human fibroblasts and in transformed GFSH-R17 rat granulosa cells in vitro. Mutat Res 583:178-183

Ellgaard L, Helenius A (2003) Quality control in the endoplasmic reticulum. Nat Rev Mol Cell Biol 4:181-191

Franzellitti S, Valbonesi P, Ciancaglini N, Biondi C, Contin A, Bersani F et al (2010) Transient DNA damage induced by high-frequency electromagnetic fields (GSM $1.8 \mathrm{GHz}$ ) in the human trophoblast HTR-8/SVneo cell line evaluated with the alkaline comet assay. Mutat Res 683:35-42. doi:S0027-5107(09)00297-8

Friedman J, Kraus S, Hauptman Y, Schiff Y, Seger R (2007) Mechanism of short-term ERK activation by electromagnetic fields at mobile phone frequencies. Biochem J 405:559-568

Gerner C, Vejda S, Gelbmann D, Bayer E, Gotzmann J, SchulteHermann R et al (2002) Concomitant determination of absolute values of cellular protein amounts, synthesis rates, and turnover rates by quantitative proteome profiling. Mol Cell Proteomics $1: 528-537$

Hardell L, Carlberg M, Soderqvist F, Mild KH, Morgan LL (2007) Long-term use of cellular phones and brain tumours: increased risk associated with use for $>$ or $=10$ years. Occup Environ Med 64:626-632 
Hardell L, Carlberg M, Soderqvist F, Hansson MK (2008) Meta-analysis of long-term mobile phone use and the association with brain tumours. Int J Oncol 32:1097-1103

Kan P, Simonsen SE, Lyon JL, Kestle JR (2008) Cellular phone use and brain tumor: a meta-analysis. J Neurooncol 86:71-78

Karinen A, Heinavaara S, Nylund R, Leszczynski D (2008) Mobile phone radiation might alter protein expression in human skin. BMC Genomics 9:77

Koulich E, Li X, Demartino GN (2008) Relative structural and functional roles of multiple deubiquitylating proteins associated with mammalian 26S proteasome. Mol Biol Cell 19:1072-1082

Kundi M, Mild K, Hardell L, Mattsson MO (2004) Mobile telephones and cancer-a review of epidemiological evidence. J Toxicol Environ Health B Crit Rev 7:351-384

Lee JS, Huang TQ, Kim TH, Kim JY, Kim HJ, Pack JK et al (2006) Radiofrequency radiation does not induce stress response in human T-lymphocytes and rat primary astrocytes. Bioelectromagnetics 27:578-588

Leszczynski D, Joenvaara S, Reivinen J, Kuokka R (2002) Non-thermal activation of the hsp27/p38MAPK stress pathway by mobile phone radiation in human endothelial cells: molecular mechanism for cancer- and blood-brain barrier-related effect. Differentiation 70:120-129

Litovitz TA, Montrose CJ, Goodman R, Elson EC (1990) Amplitude windows and transiently augmented transcription from exposure to electromagnetic fields. Bioelectromagnetics 11:297-312

Litovitz TA, Penafiel LM, Farrel JM, Krause D, Meister R, Mullins JM (1997) Bioeffects induced by exposure to microwaves are mitigated by superposition of ELF noise. Bioelectromagnetics $18: 422-430$

Maes A, Collier M, Slaets D, Verschaeve L (1996) 954 MHz microwaves enhance the mutagenic properties of mitomycin C. Environ Mol Mutagen 28:26-30

Mild KH, Wilen J, Mattsson MO, Simko M (2009) Background ELF magnetic fields in incubators: a factor of importance in cell culture work. Cell Biol Int 33:755-757

Nylund R, Leszczynski D (2004) Proteomics analysis of human endothelial cell line EA.hy926 after exposure to GSM 900 radiation. Proteomics 4:1359-1365

Perentesis JP, Phan LD, Gleason WB, LaPorte DC, Livingston DM, Bodley JW (1992) Saccharomyces cerevisiae elongation factor 2. Genetic cloning, characterization of expression, and G-domain modeling. J Biol Chem 267:1190-1197

Rabilloud T, Strub JM, Luche S, Van DA, Lunardi J (2001) A comparison between Sypro Ruby and ruthenium II tris (bathophenanthroline disulfonate) as fluorescent stains for protein detection in gels. Proteomics 1:699-704
Repacholi MH, Basten A, Gebski V, Noonan D, Finnie J, Harris AW (1997) Lymphomas in E mu-Pim1 transgenic mice exposed to pulsed 900 MHZ electromagnetic fields. Radiat Res 147:631-640

Rothman KJ, Loughlin JE, Funch DP, Dreyer NA (1996) Overall mortality of cellular telephone customers. Epidemiology 7:303-305

Sadetzki S, Chetrit A, Jarus-Hakak A, Cardis E, Deutch Y, Duvdevani $S$ et al (2008) Cellular phone use and risk of benign and malignant parotid gland tumors - a nationwide case-control study. Am J Epidemiol 167:457-467

Sanchez S, Masuda H, Ruffie G, De Gannes FP, Billaudel B, Haro E et al (2008) Effect of GSM-900 and -1800 signals on the skin of hairless rats. III: Expression of heat shock proteins. Int J Radiat Biol 84:61-68

Schuderer J, Samaras T, Oesch W, Spät D, Kuster N (2004) High peak SAR exposure unit with tight exposure and environmental control for in vitro experiments at $1800 \mathrm{MHz}$. IEEE Trans MTT 52:2057-2066

Schwarz C, Kratochvil E, Pilger A, Kuster N, Adlkofer F, Rudiger HW (2008) Radiofrequency electromagnetic fields (UMTS, 1, $950 \mathrm{MHz}$ ) induce genotoxic effects in vitro in human fibroblasts but not in lymphocytes. Int Arch Occup Environ Health 81:755767

Speit G, Schutz P, Hoffmann H (2007) Genotoxic effects of exposure to radiofrequency electromagnetic fields (RF-EMF) in cultured mammalian cells are not independently reproducible. Mutat Res 626:42-47

Traxler E, Bayer E, Stockl J, Mohr T, Lenz C, Gerner C (2004) Towards a standardized human proteome database: quantitative proteome profiling of living cells. Proteomics 4:1314-1323

Utteridge TD, Gebski V, Finnie JW, Vernon-Roberts B, Kuchel TR (2002) Long-term exposure of E-mu-Pim1 transgenic mice to 898.4 MHz microwaves does not increase lymphoma incidence. Radiat Res 158:357-364

Valberg PA (1997) Radio frequency radiation (RFR): the nature of exposure and carcinogenic potential. Cancer Causes Control $8: 323-332$

Verschaeve L, Heikkinen P, Verheyen G, Van Gorp U, Boonen F, Vander PF et al (2006) Investigation of co-genotoxic effects of radiofrequency electromagnetic fields in vivo. Radiat Res 165:598-607

White IR, Pickford R, Wood J, Skehel JM, Gangadharan B, Cutler P (2004) A statistical comparison of silver and SYPRO Ruby staining for proteomic analysis. Electrophoresis 25:3048-3054

Yilmaz F, Dasdag S, Akdag MZ, Kilinc N (2008) Whole-body exposure of radiation emitted from $900 \mathrm{MHz}$ mobile phones does not seem to affect the levels of anti-apoptotic bcl-2 protein. Electromagn Biol Med 27:65-72 